\title{
Variation of Focal Parameters and Medium Characteristics During Small Earthquakes
}

\author{
Wenlong Liư ${ }^{1}$, Yucheng Liu ${ }^{2, *}$ \\ ${ }^{1}$ Shanghai Earthquake Administration, Shanghai, 200062, China \\ ${ }^{2}$ Department of Mechanical Engineering University of Louisiana, Lafayette, LA70504, USA
}

\begin{abstract}
In earthquake prediction, strong earthquakes are usually preceded by a series of small earthquakes. Thus, correct identification of those small earthquakes characteristics tell precursor observations and will lead to accurate prediction and judgement of impending main shocks. This paper discusses seismic source dynamic parameters, medium and rupture characteristics, and their variations during small earthquakes. Focal mechanism and its variation before and after main shock are also demonstrated along with several seismic examples to summarize the change of rupture characteristics (primary rupture direction, ambient shear stress, and waveform's temporal) and periodicity during small and medium earthquakes.
\end{abstract}

Keywords focal mechanism, seismic source parameters, medium characteristics, rupture characteristics, small and medium earthquakes

\section{Introduction}

After Tangshan earthquake, Hua[1] used all first motion data of $\mathrm{P}$ wave occurred within $360 \mathrm{~km}$ from its epicenter to make comprehensive focal plane mechanism. This data was recorded by Baijiatuan (since 1958) and Beianhe (since 1975) observatories. It was found that the mechanism could not be solved during 1958 to 1971 because the contradiction ratio $\psi$ reached $40 \%$. After 1972, $\psi$ went down to below $20 \%$ and it was found the $P$ axis of the average major compressive stress aligned with the $\mathrm{P}$ axis of the later Tangshang M7.8 earthquake. After Tangshan earthquake, $\psi$ came back to $40 \%$ and the distribution of initial motion of small earthquakes became irregular (Fig. 1). Xu et al. [3] divided the area N38 $41^{\circ}, \mathrm{E} 114^{\circ} \sim 120^{\circ}$ into three regions and determined the average direction of the $\mathrm{P}$ axis from the comprehensive focal plan mechanism and using initial motion smoothing method, separately. The obtained $\mathrm{P}$ axis direction was consistent with Hua's results. The variation of the contradiction ratio before and after the Tangshan earthquake can also be clearly seen from the focal plane mechanism made based on the $P$ wave's initial motion data recorded by Changli observatory (Fig. 2).

It was indicated by numerous previous earthquake examples that in several years before the destructive earthquake, the directions of major compressive stress axes (P axes) of small and micro earthquakes occurred within the later destructive earthquake would become consistent, which were close to the $\mathrm{P}$ axis direction of that destructive earthquake

* Corresponding author:

yucheng.liu@louisiana.edu (YuchengLiu)

Published online at http://journal.sapub.org/geo

Copyright (C) 2012 Scientific \& Academic Publishing. All Rights Reserved and the direction of regional stress field. During that time the contradiction ratio evidently decreased. It was even found that the larger area in which the directions of $\mathrm{P}$ axes were consistent, the higher magnitude the future earthquake may have. This conclusion is an effective method in earthquake prediction. In order to explain this problem, the focal mechanism should be understood as a stress field released during earthquakes, which is the focal stress field. It is not a regional stress field and depends on the tectonic structures of the regional stress field and the local area of the hypocenter. The distribution of direction of faults can be considered as regular from the view of a large scale (> $10 \mathrm{~km})$. Therefore, the strong earthquakes, which are caused by large rupture activities, have reliable and regular focal mechanisms which are consistent with the local stress field. However, from a small scale $(<100 \mathrm{~m})$, small crevices with different directions and rate of movement spread over the entire area and inhomogeneous of the tectonics become prominent. Thus, the directions of $\mathrm{P}$ axes of small and micro earthquakes are generally disorganized. If the local stress field intensifies at some time, two conjugate small crevices in a certain area will be easy to rupture and the crevices with other directions will not. The directions of $\mathrm{P}$ axes of small and micro earthquakes become consistent. A large area in which those directions are consistent means a strong local stress field and a wider control range, and the future earthquakes occurring in that area will have higher magnitudes.

As found by seismologists of former Soviet Union, in Garm and other regions of middle Asia, the directions of $\mathrm{P}$ axes of small and micro earthquakes turned to be consistent from disorder within one and half to two years before the occurrence of medium and strong earthquakes. Moreover, those directions turned to $90^{\circ}$ at two months or a little bit 
longer before the main shock[3-5]. Such phenomena were also observed in China. For example, before the Songpan earthquake, the nodal plane solution of Songpan station showed that the directions of $\mathrm{P}$ axes started to turn from EW direction to NS direction at end of 1974. Moreover, the nodal

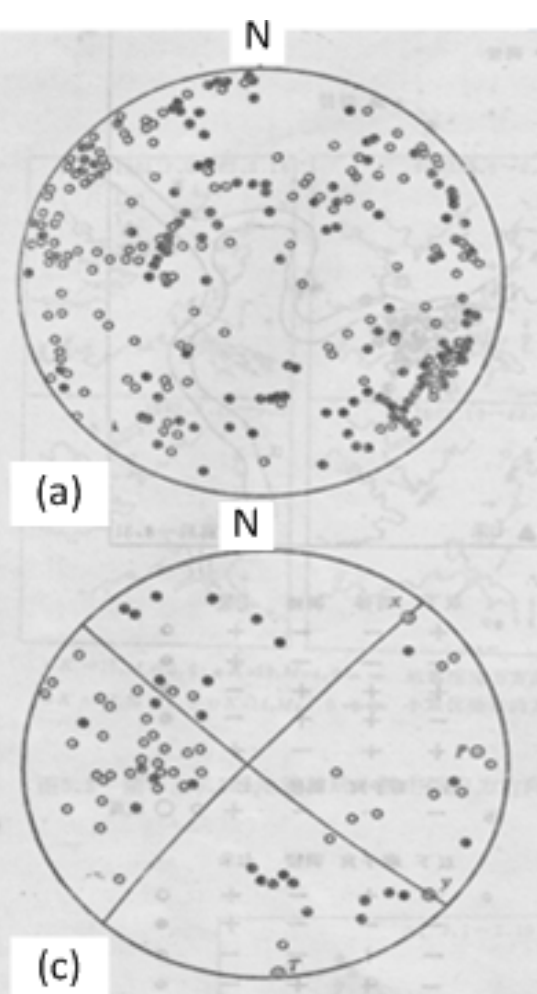

plane solution of Gangu station indicated that, from the beginning of 1971, the directions of $\mathrm{P}$ axes turned to be along NS direction from disorder status and those directions had been switching to EW direction from the beginning of 1974 till the occurrence of Songpan earthquake.

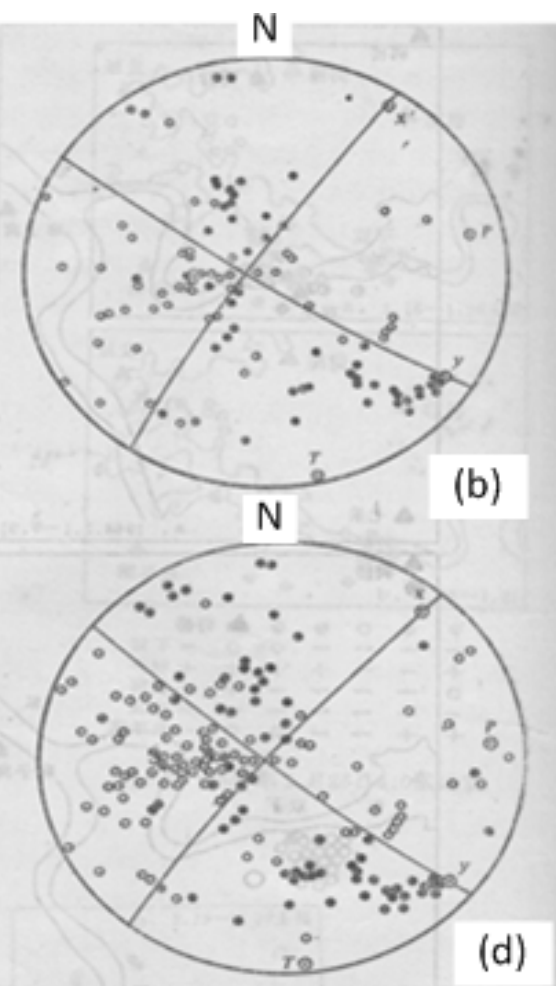

Figure 1. Comprehensive focal plane mechanism before and after Tangshan earthquake. (a) Baijiatuan 1958 1971; (b) Baijiatuan 1972 1976.7.27; (c) Beianhe 1975.9 1976.7.27; (d) both observatories from 1972 1976.7.27

Table 1. Nodal plane solutions of small earthquakes obtained from Songpan and Gangu stations

\begin{tabular}{|c|c|c|c|c|c|c|c|c|c|}
\hline \multirow[b]{2}{*}{ Station } & \multirow[b]{2}{*}{ Duration } & Nodal plane I & Nodal plane II & $\mathrm{X}$ & $\mathrm{Y}$ & $\mathrm{P}$ & $\mathrm{T}$ & $\mathrm{N}$ & \multirow[b]{2}{*}{$\psi$} \\
\hline & & $\begin{array}{l}\text { Direction/ } \\
\text { inclination }\end{array}$ & $\begin{array}{l}\text { Direction/ } \\
\text { inclination }\end{array}$ & $\begin{array}{l}\text { Position/ } \\
\text { elevation }\end{array}$ & $\begin{array}{l}\text { Position/ } \\
\text { elevation }\end{array}$ & $\begin{array}{l}\text { Position/ } \\
\text { elevation }\end{array}$ & $\begin{array}{l}\text { Position/ } \\
\text { elevation }\end{array}$ & $\begin{array}{l}\text { Position/ } \\
\text { elevation }\end{array}$ & \\
\hline \multirow{2}{*}{$\begin{array}{l}\text { Song- } \\
\text { pan }\end{array}$} & $70.7-74.11$ & $27.5^{\circ} \mathrm{NW} / 75^{\circ}$ & $308.5^{\circ} \mathrm{NE} / 55^{\circ}$ & $38.5^{\circ} / 35^{\circ}$ & $298^{\circ} / 15^{\circ}$ & $82^{\circ} / 13^{\circ}$ & $343^{\circ} / 36^{\circ}$ & $188.5^{\circ} / 51^{\circ}$ & $29 \%$ \\
\hline & 74.11-76.8 & $70^{\circ} \mathrm{NNW} / 51^{\circ}$ & $305^{\circ} \mathrm{SW} / 54^{\circ}$ & $214.5^{\circ} / 36^{\circ}$ & $341^{\circ} / 39^{\circ}$ & $8^{\circ} / 2^{\circ}$ & $275^{\circ} / 59^{\circ}$ & $99^{\circ} / 31^{\circ}$ & $25 \%$ \\
\hline \multirow{2}{*}{ Gangu } & $71.1-73.12$ & $32^{\circ} \mathrm{NW} / 50^{\circ}$ & $338^{\circ} \mathrm{NE} / 55^{\circ}$ & $69 / 35^{\circ}$ & $302^{\circ} / 40^{\circ}$ & $8 / 59^{\circ}$ & $274^{\circ} / 2^{\circ}$ & $182^{\circ} / 30^{\circ}$ & $31 \%$ \\
\hline & $74.1-76.8$ & $33^{\circ} \mathrm{SE} / 60^{\circ}$ & $318^{\circ} \mathrm{SW} / 65^{\circ}$ & $228^{\circ} / 25^{\circ}$ & $122^{\circ} / 30^{\circ}$ & $84^{\circ} / 3^{\circ}$ & $177^{\circ} / 40^{\circ}$ & $351^{\circ} / 49^{\circ}$ & $18 \%$ \\
\hline
\end{tabular}

Table 2. Directions of P axes of Haicheng earthquake and other medium and strong earthquakes as well as their precursory earthquakes

\begin{tabular}{|c|c|c|c|c|c|c|}
\hline \multirow{2}{*}{ Origin time } & \multicolumn{3}{|c|}{ Epicentral location } & \multirow{2}{*}{ Magnitude } & \multicolumn{2}{|c|}{$\mathrm{P}$ axis } \\
\hline & Longitude & Latitude & Location & & Position & Elevation \\
\hline $12 / 22 / 1974$ & $123^{\circ} 6^{\prime}$ & $41^{\circ} 25^{\prime}$ & Shenwo reservoir & 4.8 & $179^{\circ}$ & $45^{\circ}$ \\
\hline $2 / 4 / 1975$ & $122^{\circ} 48^{\prime}$ & $40^{\circ} 39^{\prime}$ & Haicheng & 7.3 & $66^{\circ}$ & $17^{\circ} 30^{\prime}$ \\
\hline $6 / 24 / 1975$ & $111^{\circ} 42^{\prime}$ & $40^{\circ} 32^{\prime}$ & Horinger & 4.4 & $120^{\circ}$ & $74^{\circ}$ \\
\hline 4/6/1976 & $112^{\circ} 12^{\prime}$ & $40^{\circ} 14^{\prime}$ & Horinger & 6.3 & $73^{\circ}$ & $2^{\circ}$ \\
\hline $10 / 14 / 1976$ & $112^{\circ} 34^{\prime}$ & $40^{\circ} 39^{\prime}$ & Liangcheng & 4.1 & $200^{\circ} 30^{\prime}$ & $41^{\circ}$ \\
\hline $10 / 17 / 1976$ & $112^{\circ} 38^{\prime}$ & $40^{\circ} 38^{\prime}$ & Liangcheng & 3.9 & $172^{\circ}$ & $2^{\circ}$ \\
\hline $2 / 2 / 1977$ & $112^{\circ} 15^{\prime}$ & $40^{\circ} 20^{\prime}$ & Horinger & 4.1 & $192^{\circ}$ & $17^{\circ} 30^{\prime}$ \\
\hline $3 / 14 / 1977$ & $112^{\circ} 30^{\prime}$ & $40^{\circ} 30^{\prime}$ & Liangcheng & 4.5 & $86^{\circ}$ & $43^{\circ}$ \\
\hline $4 / 14 / 1978$ & $117^{\circ} 24^{\prime}$ & $32^{\circ} 30^{\prime}$ & Changfeng & 2.3 & $159^{\circ}$ & $24^{\circ}$ \\
\hline $3 / 2 / 1979$ & $117^{\circ} 24^{\prime}$ & $33^{\circ} 12^{\prime}$ & Guzhen & 5.0 & $255^{\circ}$ & $45^{\circ}$ \\
\hline $5 / 10 / 1977$ & $119^{\circ} 6^{\prime}$ & $31^{\circ} 36^{\prime}$ & Lishui & 4.1 & $358^{\circ}$ & $15^{\circ} 48^{\prime}$ \\
\hline $7 / 9 / 1979$ & $119^{\circ} 18^{\prime}$ & $32^{\circ} 30^{\prime}$ & Liyang & 6.0 & $268^{\circ}$ & $40^{\circ}$ \\
\hline $7 / 31 / 1979$ & $108^{\circ} 26^{\prime}$ & $40^{\circ} 54^{\prime}$ & Urat front banner & 4.4 & $140^{\circ}$ & Very large \\
\hline $8 / 25 / 1979$ & $108^{\circ} 7^{\prime}$ & $41^{\circ} 14^{\prime}$ & Wuyuan & 6.0 & $46^{\circ}$ & Very small \\
\hline
\end{tabular}


Table 2 lists directions of $\mathrm{P}$ axes of several medium and strong earthquakes as well as their precursory earthquakes. It can be found that the $\mathrm{P}$ axis rotated about $90^{\circ}$ from precursory earthquake to the main shock and the elevation differed a lot.

From above data it can be found that at later stage of preparation process of the medium and strong earthquakes, the direction of $\mathrm{P}$ axes of the small and medium earthquakes which occurred in focal region and its marginal area might turned a large angle from the formed dominating direction. Because earthquakes usually occur in a comparatively small space and during a short time-period, therefore such turning of the $\mathrm{P}$ axis may not be found from the focal plane solutions obtained from a single observatory. However, if the observatory and all its data about the initial motion of $\mathrm{P}$ wave are located in the seismogenic zones of medium and strong earthquakes, there is a possibility to detect such turning or at least the increase in the contradiction ratio $\psi$ can be found. Based on this phenomenon, the origin time and epicentral position of future medium and strong earthquakes can be timely estimated if it is found that the directions of the $\mathrm{P}$ axes become consistent and render an obvious tendency of turning. The mechanism that causes the turning of the $\mathrm{P}$ axes was explained by Brady[6] as a characteristic of closing period of rock cracks and explained by Gupta[7] in terms of vertical migration of seismic activity.

\section{Seismic Source Dynamic Parameters}

Zhu et al.[8] investigated the stress drop $\Delta \sigma$ and focal radius a of micro earthquakes $\left(\mathrm{M}_{\mathrm{L}} 1.5 \sim 2.9\right)$ occurred from Apr-2-1971 to Feb-14-1977 (before and after the Tangshan earthquake) using spherical explosive source model (section 3.3.3.2). They found that before the $M_{L} 7.8$ Tangshan earthquake, $\Delta \sigma$ of small earthquakes occurred in the region of Ninghe-Tangshan-Luanxianwere comparatively high and had an average value 22 bar. After the main shock, that average value dropped to 12 bar, however, a small earthquake occurred near Ninghe and two small earthquakes occurred at north to Luanxian still had high $\Delta \sigma$ values. Soon after, two strong aftershocks with M6.9 and M6.0 occurred in these two areas. It was also found that the average focal radius of those small earthquakes before the Tangshan earthquake was $40 \mathrm{~m}$, which increased to $49 \mathrm{~m}$ after it.

Lin et al.[9] studied $\Delta \sigma$ and a of partial $\mathrm{M}_{\mathrm{L}} 1.5 \sim$ 2.9earthquakes occurred from May-25-1970 to Jun-25-1977 in the areas of Tangshan-Fengnan-Ninghe-Tianzhuang using circular shear dislocation model (section 3.3.1). It was found that the average $\Delta \sigma$ was 2.3 bar before the Tangshan earthquake and the value dropped to $0.2 \sim 0.3$ bar after it. The average focal radius (a) was $490 \mathrm{~m}$ before that earthquake and the radius became $540 \mathrm{~m}$ after the main shock.

Such phenomena were also found from the small earthquakes occurred before and after the Haicheng earthquake: $\Delta \sigma$ of small earthquakes before the main shock are higher than $\Delta \sigma$ of those after the main shock; focal sizes of small earthquakes before the main shock are lower than those after the main shock; the distribution area of such earthquakes is by and large consistent with the aftershock area. However, other researchers found that there were not obvious variations before and after the Haicheng earthquake in $\Delta \sigma$ and focal size[10]. Even worse, different results were obtained by different researchers who studied the same earthquake using same focal source model (see section 1.3.1). Tsujiura [11] and Bakun[12] studied foreshock sequences of several earthquakes occurred in Japan and United States, and found different results in comparing $\Delta \sigma$ of the foreshocks to that of the main shock.

Chen et al. introduced rupture mechanics into the determination of the focal dynamic parameters[13] and studied the variation of ambient shear stress $\left(\tau_{0}\right)$ before and after Tangshan earthquake[14]. It was concluded by them that the $\tau_{0}$ is higher before the main shock and lower after it. This conclusion is well accepted in China.

$\tau_{0}$ is basically the same as $\Delta \sigma$. In physics, $\Delta \sigma$ is the difference of focal stresses before and after the shock. From the view of rupture mechanics, after the earthquake, the focal medium entirely broke so that the stress is zero. In this case, $\Delta \sigma$ equals the focal stress before the earthquake. Also, by using the cracks (type II) of a 2D plane strain as the seismic rupture model, the focal stress before the earthquake $\Delta \sigma$ is the preseismic ambient share stress $\tau_{0}$. In determining $\Delta \sigma$, the first step is to obtain seismic moment and focal radius in the frequency or time domain based on the circular shear dislocation model. Next, $\Delta \sigma$ along with the average and maximum dislocation can be calculated from elasticity using the following equations

$$
\left\{\begin{array}{l}
\Delta \sigma=\frac{7 m_{0}}{16 a^{3}} \\
\Delta \bar{u}=\frac{16 \Delta \sigma \cdot a}{7 \pi \mu} \\
\Delta u_{m}=\frac{3 \Delta \bar{u}}{2}
\end{array}\right.
$$

The first step in calculating $\tau_{0}$ is exactly the same as the first step of determining $\Delta \sigma$. Based calculated seismic momentum and focal radius, $\tau_{0}$ can be calculated based on rupture mechanics theories as

$$
\left\{\begin{array}{l}
m_{o}=\frac{(1-v) \pi \tau_{0}^{2}(2 a)^{3}}{3(2-v) \tau_{y}} \\
M_{s}=2 \lg (2 a)+\frac{1}{1.5}\left[\frac{\lg 4(1-v) \tau_{0}^{2} \eta}{3(2-v) \mu}-11.8\right] \\
\frac{\Delta \bar{u}}{2 a}=\frac{4(1-v) \tau_{0}^{2}}{3(2-v) \pi \mu \tau_{y}}
\end{array}\right.
$$

In above equation, $v$ is Poisson's ratio $(v=0.252)$; $\mu$ is shear modulus $(\mu=33 \mathrm{GPa}) ; \eta$ is radiation efficiency of the seismic waves $(\eta=0.05) ; \tau_{\mathrm{y}}$ is yield strength $\left(\tau_{\mathrm{y}}=200 \mathrm{MPa}\right)$. Comparing Eqn. (2) to (1) and we can see that $\tau_{0}$ only differs from $\Delta \sigma$ by a coefficient. 


\section{Variation of Characteristics of Media}

Variation of $\mathrm{Q}$ value before medium and strong earthquakes

The quality factor of medium, Q, is a dimentionless parameter that describes the seismic wave absorption capability of the medium. A medium with excellent integrity will absorb less seismic waves, and therefore has a high $\mathrm{Q}$ value, which can be used to predict future earthquake tendency in three ways.

(1). Q can be applied in creating seismic ground motion parameter zonation map and used for long-term prediction. In the areas with high $\mathrm{Q}$ values, the expected maximum magnitude of its potential hypocenters will be high; otherwise, the maximum magnitude will be low. Fig. 2a shows the distribution of the $\mathrm{Q}$ value in Shanghai and vicinity and Fig. $2 \mathrm{~b}$ displays the distribution of potential seismic sources. By comparing the two figures, it can be found that the distributions are consistent with each other[15].
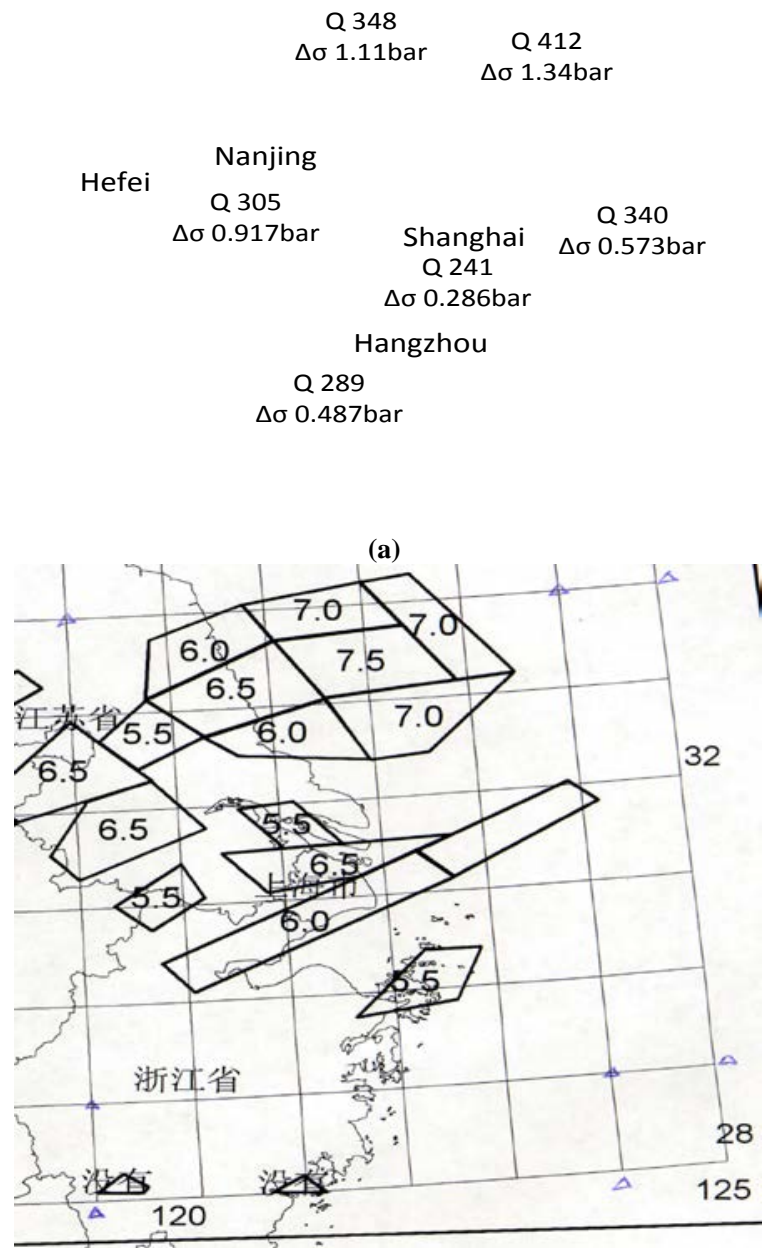

(b)

Figure 2. Distribution of (a) Q value and (b) potential seismic sources in Shanghai and vicinity
(2). In medium and short term prediction, several earthquake examples indicated that the $\mathrm{Q}$ value was high in the epicentral area before the main shock and became lower after the earthquake. Fig. 3 shows the distribution of $\mathrm{Q}$ values before and after the Haicheng earthquake, which were recorded by local observatories[16]. From that figure, it can be found that before the earthquake the epicentral area had higher $\mathrm{Q}$ values while after it the $\mathrm{Q}$ values evidently reduced in the areas northeast and southwest to the epicenter. Similarly, previous study revealed that the peak $Q$ value before the Tangshan earthquake was 660 and after the main shock, it went down to 606. That value was further reduced to 357 after the M6.9 Ninghe earthquake on November 15, 1976. Since then, there has been no $M \geq 7.0$ earthquake occurring in that area[17].

(3). Q can also be used to determine the earthquake type. Higher Q value means that the medium has better integrity, which can accumulate a large amount of energy therefore leading to strong earthquakes. On the contrary, the medium has lower $\mathrm{Q}$ values does not accumulate enough energy, and can only cause small ruptures instead of strong earthquakes. The occurrence of strong earthquake breaks the medium near the hypocenter, therefore reducing the local Q value.

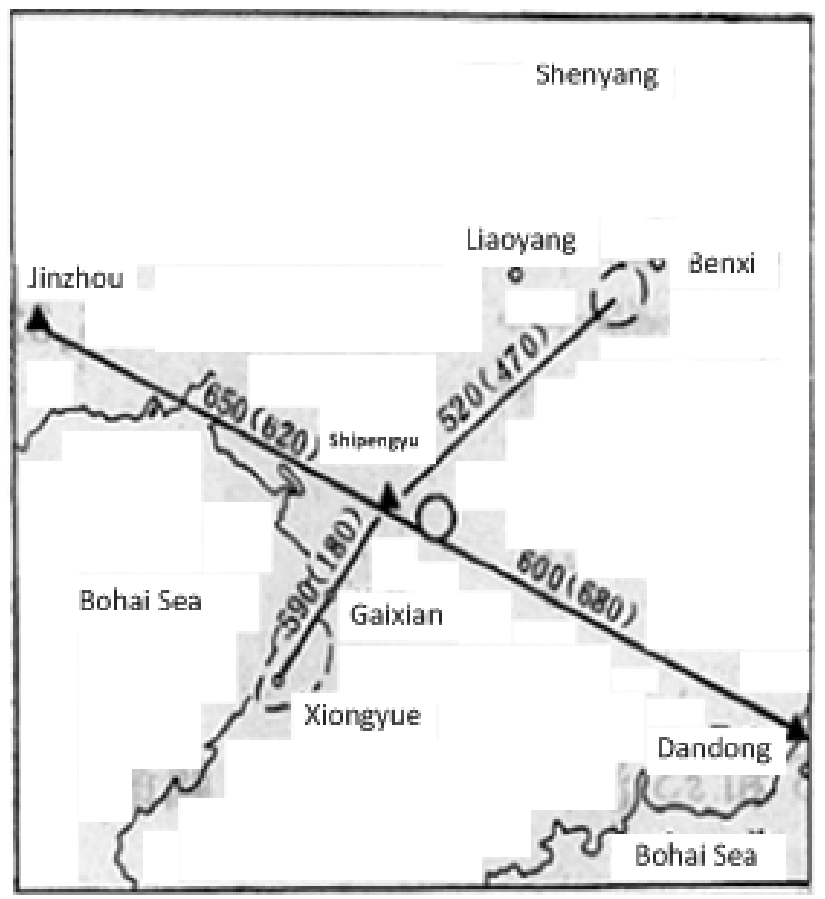

Figure 3. Distribution of $\mathrm{Q}$ values before and after Haicheng earthquake

\subsection{Microtremor}

If the enlargement factor of a seismograph is turned higher, regular, periodic vibrations will be shown on the seismogram even without earthquake. Such vibrations whose period ranges from 0.1 second to several minutes are called microtremor. In order to acquire a higher enlargement factor while not to affect the seismic record, the enlargement factor is usually set to a level that the double amplitude of the induced microtremor will not exceed $1 \mathrm{~mm}$. Abnormal microtremor was found before a number of strong earthquakes, 
which has drawn a lot of attention.

For example, the abnormal microstremor was detected before the Haicheng earthquake[16]. The daily amplitude of microtremor was determined following below steps. Three maximum amplitudes were selected in 10 minutes before and after 12:00 am and 12:00 pm that day, separately. Two average values were calculated which represented the amplitudes at 12:00 am and 12:00 pm, the average value of the two average amplitudes is the daily amplitude of microtremor. As shown in Fig. 4, the amplitude of South-North microtremor recorded by short period seismograph of Shipengyu seismic station, which is $20 \mathrm{~km}$ from the epicenter, decreased in two days before the Haicheng earthquake. That value slightly increased at 10 hours before the main shock. Similar variation was also observed from the records of Dandong station, which is $100 \mathrm{~km}$ from the epicenter. The amplitudes of microtremor recorded by other local stations did not show evident variation.

As found by Zhu[18], before the Tangshan earthquake, the amplitude of microtremor recorded by Changli station, which was $80 \mathrm{~km}$ from the epicenter, dramatically decreased (Fig. 5). The decreasing of the microtremor's amplitude in a short period was also detected before several strong aftershocks. However, no obvious variation in such amplitude was observed from distant observatories.

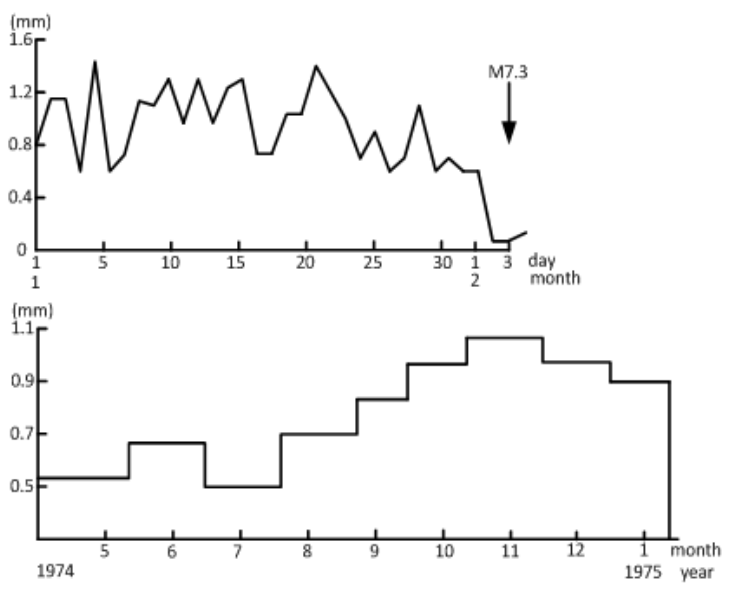

Figure 4. Amplitude of microtremor recorded by Shipengyu station

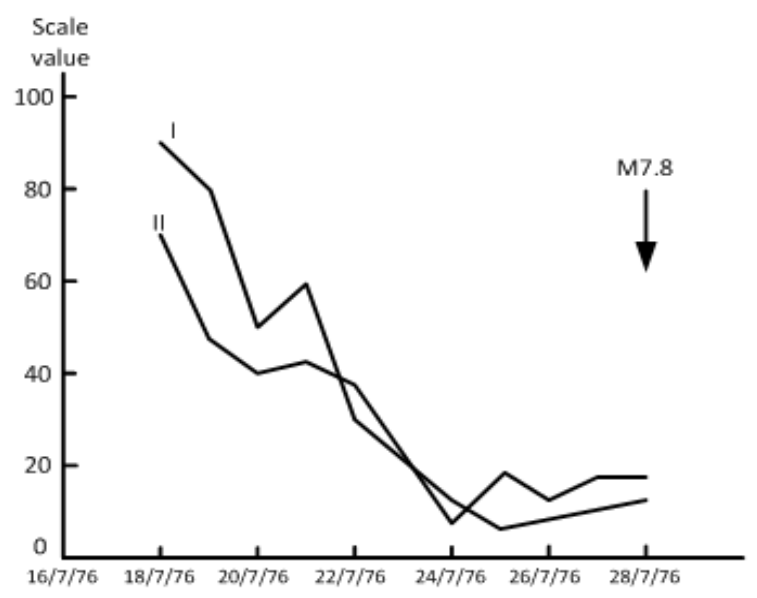

Figure 5. Amplitude of microtremor recorded by Changli station
Zhu[16] also discussed peculiar undulation occurred before medium and strong earthquakes. For example, during tens of hours to ten days before the earthquakes with magnitude higher than Ms4 which occurred in Beijing area, a peculiar undulation was observed from seismograms recorded by a SKZ seismograph which was located within 250 $\mathrm{km}$ from the epicenter. Such undulation discretely appeared along the N-S and E-W horizontal directions (especially the $\mathrm{N}-\mathrm{S}$ direction). Its waveform was smooth and rendered as shortwave columns with period ranging from 10 to 20 seconds. Its amplitude was three to five times as large as the amplitude of the microtremor. Zhu studied $22 \mathrm{Ms} \geq 4$ earthquakes occurred during 1957 to 1971 and found that such peculiar undulation had appeared before 18 earthquakes. Moreover, there were 31 peculiar undulations being detected in 1972 and 1973. During that period, $16 \mathrm{Ms} \geq 4$ earthquakes occurred and 15 of them were relevant to such peculiar undulation.

Before the Great Chilean earthquake of May 22, 1960 (Ms = 8.9), long-period strain seismogram recorded at Pasadena $(10,000 \mathrm{~km}$ from the epicenter) clearly showed unusually long-period (300 - $600 \mathrm{sec})$ wave arriving at the $\mathrm{P}$ time of a large foreshock (Ms $=6.8$ ) which occurred about 15 minutes before the main shock (see Fig. 6)[19].

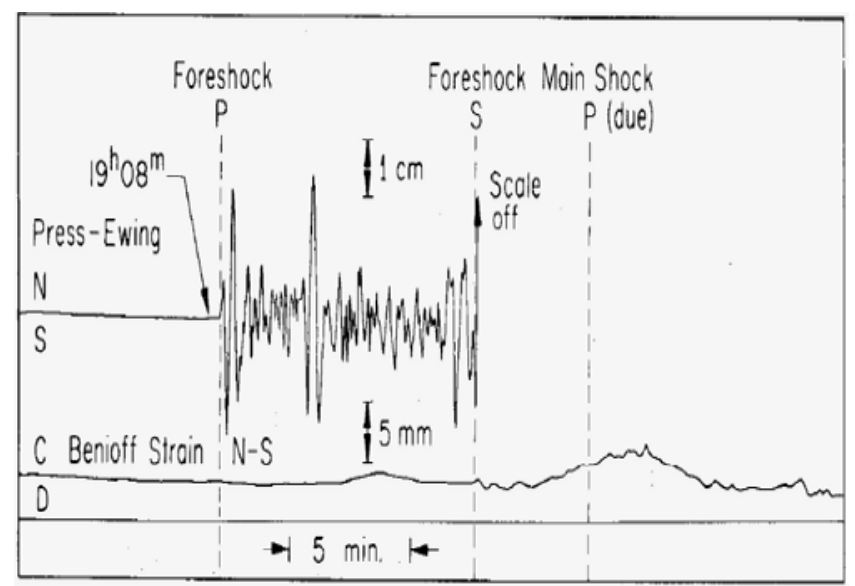

Figure 6. Blow-up of the precursor on the strain seismogram, the PressEwing seismogram is shown for comparison

The variation of the amplitude of microtremor reflects the change of characteristics of the media. Kanamori and Cipar [20] considered such unusual wave that occurred before the main shock indicated a large slow deformation in the epicentral area prior to the major failure. However, Zhu et al. [17] insisted that such wave is caused by the new pulsation source formed from upwelling of underground hydrothermal fluids and acoustic emission.

\section{Epicentral Rupture Characteristics}

Assuming an earthquake with nonsymmetric bilateral rupture and the rupture lengths for the two sides are $\mathrm{L}_{0}$ (for primary rupture with long side) and $L_{\pi}$ (for secondary rupture with short side). Major epicentral rupture characteristics 
include the direction of the primary rupture $\mathrm{L}_{0}$ and the ratio of the length of the primary rupture and the total length of the rupture $\mathrm{L}_{0} / \mathrm{L}$, where $\mathrm{L}=\mathrm{L}_{0}+\mathrm{L}_{\pi}$. The value $\mathrm{L}_{0} / \mathrm{L}$ varies between 0.5 and 1 , where 0.5 indicates a symmetric bilateral rupture, and 1 means a unilateral rupture. Detailed methods of calculating that ratio will be introduced in a separate paper. Width of Fourier spectrum (w) is defined as the bandwidth which is $70 \%$ of the maximum spectral amplitude. w represents the complexity of seismic waves. The wider $\mathrm{w}$ is, the more frequency the seismic wave has, the more complicated the rupture process should be, and therefore the more unevenly the epicentral medium and stress are distributed.

Liu et al.[21,22] studied four earthquakes with magnitude around M6.0 which occurred in southeastern China since 1970. Those earthquakes are: M6.0 Liyang earthquake July 9, 1979; M5.9 Heze earthquake November 7, 1983; M6.2 southern Yellow Sea earthquake May 21, 1984; and M6.1 and M6.2 northern Gulf earthquakes December 31, 1994 and January 10, 1995, respectively. In studying those earthquakes, six seismic wave parameters were investigated using seismic wave method, error estimations were also discussed. Those parameters are: rupture characteristics $\left(\mathrm{L}_{0} / \mathrm{L}\right)$, primary rupture directions, ambient shear stress $\tau$, temporal periodicity of waveform r, Q values for $\mathrm{P}$ waves, and the width of Fourier spectrum w. In their study, the characteristics seismic wave parameters of abnormal earthquakes occurred on seismic gap and belt were studied to define the single foreshock in order to reveal the radiation of the seismic wave of the single foreshock, which is difficult to be identified before the main shock by using traditional seismic activity method.

Through their investigation, following conclusions were obtained.

(1) The primary rupture directions of earthquakes occur on seismogenic zones are parallel to the coming main shock's nodal plane and they either are tangent to the zone or point outside the zone. However, during the normal periods, the primary rupture directions are disorganized.

Let's use the Liyang M6.0 earthquake as an example. Table 3 lists the calculated results of rupture characteristics of medium and small earthquakes that occurred before and after the main shock. In that table, $\lambda$ and $\sigma$ denote the azimuth of the primary rupture directions and its root-mean-square error (RMSE), respectively. If distribution of the local seismic stations was not ideal, three or more possible primary rupture directions could be found. $\lambda$ and $\sigma$ values were not selected for such cases. $n$ is the number of seismic observatories. Certainty factor (CF) of the primary rupture direction was defined as: $\mathrm{CF}=\mathrm{I}$ when $\sigma \leq 15^{\circ}$ and only one primary rupture direction was determined; $\mathrm{CF}=\mathrm{II}$ when $15^{\circ}<\sigma \leq 30^{\circ}$ and only one primary rupture direction was determined; CF = III when two possible primary directions were found.

Table 3. Rupture characteristics of medium and small earthquakes occurred before and after the Liyang M6.0 earthquake

\begin{tabular}{|c|c|c|c|c|c|c|c|c|c|c|}
\hline No & Date & Time & Longitude & Latitude & $\mathrm{M}_{\mathrm{L}}$ & $L_{0} / L$ & $\lambda_{1}, \sigma_{1}\left({ }^{\circ}\right)$ & $\lambda_{2}, \sigma_{2}\left({ }^{\circ}\right)$ & $\mathrm{n}$ & CF \\
\hline \multicolumn{11}{|c|}{ Before Liyang M6.0 earthquake } \\
\hline 1 & $1977-05-10$ & $11: 56$ & $119^{\circ} 13^{\prime}$ & $31^{\circ} 58^{\prime}$ & 4.6 & 0.95 & & & 5 & \\
\hline 2 & $1977-09-10$ & $21: 35$ & $117^{\circ} 56^{\prime}$ & $32^{\circ} 59^{\prime}$ & 2.8 & 1.0 & $331.4,22.5$ & & 3 & II \\
\hline 3 & $1977-11-08$ & 21:05 & $117^{\circ} 30^{\prime}$ & $32^{\circ} 00^{\prime}$ & 2.6 & 0.87 & $317,8.7$ & & 4 & $\mathrm{I}$ \\
\hline 4 & $1977-11-28$ & $05: 22$ & $116^{\circ} 53^{\prime}$ & $32^{\circ} 45^{\prime}$ & 2.1 & 1.0 & & & 2 & \\
\hline 5 & 1978-01-28 & $13: 01$ & $117^{\circ} 32^{\prime}$ & $32^{\circ} 11^{\prime}$ & 2.8 & 1.0 & $205.3,12.1$ & & 3 & $\mathrm{I}$ \\
\hline 6 & $1978-01-28$ & $13: 48$ & $117^{\circ} 37^{\prime}$ & $32^{\circ} 11^{\prime}$ & 3.1 & 0.88 & $290.8,7.2$ & $28.3,7.2$ & 5 & III \\
\hline 7 & $1978-02-16$ & $08: 42$ & $117^{\circ} 32^{\prime}$ & $31^{\circ} 59^{\prime}$ & 2.8 & 1.0 & & & 2 & \\
\hline 8 & 1978-03-26 & $04: 03$ & $117^{\circ} 31^{\prime}$ & $32^{\circ} 02^{\prime}$ & 3.3 & 0.9 & $302.1,9.4$ & & 6 & $\mathrm{I}$ \\
\hline 9 & 1978-03-26 & $20: 51$ & $118^{\circ} 43^{\prime}$ & $33^{\circ} 15^{\prime}$ & 3.6 & 0.88 & $309.1,17.7$ & & 7 & II \\
\hline 10 & 1978-04-14 & $04: 40$ & $117^{\circ} 21^{\prime}$ & $32^{\circ} 29^{\prime}$ & 3.0 & 1.0 & & & 2 & \\
\hline 11 & 1978-05-28 & $14: 13$ & $117^{\circ} 32^{\prime}$ & $32^{\circ} 02^{\prime}$ & 3.2 & 0.93 & $186.6,5$ & $116.6,5$ & 5 & III \\
\hline 12 & 1978-06-25 & $04: 34$ & $119^{\circ} 17^{\prime}$ & $31^{\circ} 27^{\prime}$ & 3.0 & 1.0 & & & 2 & \\
\hline 13 & 1978-07-06 & $11: 44$ & $120^{\circ} 57^{\prime}$ & $32^{\circ} 43^{\prime}$ & 3.7 & 0.93 & $303.4,17.3$ & & 5 & II \\
\hline 14 & 1978-07-17 & $00: 48$ & $120^{\circ} 50^{\prime}$ & $32^{\circ} 45^{\prime}$ & 3.9 & 0.78 & $306.7,19.7$ & & 5 & II \\
\hline 15 & 1978-07-17 & $00: 52$ & $120^{\circ} 59^{\prime}$ & $32^{\circ} 46^{\prime}$ & 3.3 & 0.73 & $42.7,13.7$ & & 4 & $\mathrm{I}$ \\
\hline 16 & 1978-07-27 & $20: 30$ & $117^{\circ} 27^{\prime}$ & $31^{\circ} 57^{\prime}$ & 3.1 & 0.90 & $247.4,15$ & $352.4,0$ & 4 & III \\
\hline 17 & 1978-11-24 & $23: 38$ & $117^{\circ} 27^{\prime}$ & $32^{\circ} 22^{\prime}$ & 3.3 & 0.70 & $212.7,25$ & & 4 & II \\
\hline 18 & 1978-12-01 & 01:03 & $119^{\circ} 37^{\prime}$ & $31^{\circ} 43^{\prime}$ & 3.3 & 1.0 & 301,30 & & 3 & II \\
\hline 19 & 1978-12-19 & 08:07 & $119^{\circ} 00^{\prime}$ & $32^{\circ} 22^{\prime}$ & 2.8 & 1.0 & & & 2 & \\
\hline 20 & 1978-12-23 & $10: 53$ & $117^{\circ} 36^{\prime}$ & $32^{\circ} 10^{\prime}$ & 3.3 & 1.0 & $214.2,17.3$ & & 4 & II \\
\hline 21 & 1979-01-25 & $18: 25$ & $120^{\circ} 12^{\prime}$ & $33^{\circ} 20^{\prime}$ & 3.1 & 0.93 & $20.6,7.5$ & & 4 & $\mathrm{I}$ \\
\hline 22 & 1979-04-16 & $05: 27$ & $117^{\circ} 04^{\prime}$ & $32^{\circ} 57^{\prime}$ & 2.2 & 1.0 & & & 2 & \\
\hline 23 & 1979-04-28 & 09:15 & $121^{\circ} 27^{\prime}$ & $32^{\circ} 53^{\prime}$ & 3.0 & 1.0 & & & 2 & \\
\hline \multicolumn{11}{|c|}{ After Liyang M6.0 earthquake } \\
\hline 24 & 1992-01-25 & 06:37 & $119^{\circ} 51^{\prime}$ & $31^{\circ} 55^{\prime}$ & 3.2 & 0.76 & $45.7,0$ & & 6 & $\mathrm{I}$ \\
\hline 25 & 1992-03-20 & $23: 10$ & $120^{\circ} 04^{\prime}$ & $32^{\circ} 08^{\prime}$ & 2.8 & 0.90 & $199.7,7.2$ & $327.2,7.2$ & 5 & III \\
\hline 26 & 1992-05-29 & $16: 33$ & $120^{\circ} 38^{\prime}$ & $33^{\circ} 29^{\prime}$ & 3.3 & 1.0 & & & 2 & \\
\hline 27 & 1992-06-27 & $07: 35$ & $117^{\circ} 46^{\prime}$ & $32^{\circ} 30^{\prime}$ & 3.0 & 1.0 & $243.3,15$ & $153.3,15$ & 4 & III \\
\hline 28 & 1992-09-13 & 03:47 & $117^{\circ} 07^{\prime}$ & $32^{\circ} 08^{\prime}$ & 2.5 & 0.90 & $191.4,0$ & & 3 & $\mathrm{I}$ \\
\hline 29 & 1992-10-25 & $17: 46$ & $120^{\circ} 34^{\prime}$ & $32^{\circ} 45^{\prime}$ & 3.5 & 1.0 & $135.5,12$ & & 8 & $\mathrm{I}$ \\
\hline
\end{tabular}


Table 4. Rupture characteristics of medium and small earthquakes occurred before and after the southern Yellow Sea M6.2 earthquake

\begin{tabular}{|c|c|c|c|c|c|c|c|c|c|c|}
\hline No & Date & Time & Longitude & Latitude & $\mathrm{M}_{\mathrm{L}}$ & $L_{0} / L$ & $\lambda_{1}, \sigma_{1}\left(^{\circ}\right)$ & $\lambda_{2}, \sigma_{2}\left({ }^{\circ}\right)$ & $n$ & $\mathrm{CF}$ \\
\hline \multicolumn{11}{|c|}{ Before southern Yellow Sea M6.2 earthquake } \\
\hline 1 & 1978-07-06 & 11:44 & $120^{\circ} 57^{\prime}$ & $32^{\circ} 43^{\prime}$ & 3.7 & 1.0 & $14.8,0$ & $134.8,0$ & 4 & III \\
\hline 2 & $1978-07-17$ & $22: 48$ & $120^{\circ} 50^{\prime}$ & $32^{\circ} 45^{\prime}$ & 3.9 & 0.90 & $47.4,8.5$ & $138.9,8.8$ & 5 & III \\
\hline 3 & 1979-01-04 & $18: 28$ & $120^{\circ} 30^{\prime}$ & $33^{\circ} 50^{\prime}$ & 4.3 & 1.0 & $120.7,5.8$ & & 4 & I \\
\hline 4 & 1981-01-11 & $21: 30$ & $120^{\circ} 36^{\prime}$ & $33^{\circ} 34^{\prime}$ & 3.7 & 0.95 & $155.9,5.2$ & $220.9,5.2$ & 7 & III \\
\hline 5 & $1983-09-10$ & $07: 47$ & $122^{\circ} 29^{\prime}$ & $34^{\circ} 14^{\prime}$ & 3.5 & 0.73 & & & 5 & \\
\hline 6 & 1983-09-25 & $14: 30$ & $120^{\circ} 07^{\prime}$ & $32^{\circ} 51^{\prime}$ & 3.5 & 0.94 & $238.8,11.6$ & & 9 & $\mathrm{I}$ \\
\hline 7 & $1983-10-07$ & $19: 38$ & $122^{\circ} 19^{\prime}$ & $34^{\circ} 26^{\prime}$ & 3.7 & 0.80 & $229.4,17.3$ & & 3 & II \\
\hline 8 & $1983-10-11$ & $22: 36$ & $121^{\circ} 20^{\prime}$ & $34^{\circ} 35^{\prime}$ & 3.9 & 1.0 & $313.9,4.3$ & $220.5,4.3$ & 10 & III \\
\hline 9 & 1983-10-14 & 05:00 & $121^{\circ} 16^{\prime}$ & $34^{\circ} 40^{\prime}$ & 3.3 & 1.0 & $313.9,15$ & $223.9,15$ & 4 & III \\
\hline 10 & 1983-10-19 & $14: 25$ & $121^{\circ} 25^{\prime}$ & $33^{\circ} 49^{\prime}$ & 4.1 & 0.96 & $233.3,12.4$ & & 8 & I \\
\hline 11 & 1984-05-16 & $17: 16$ & $120^{\circ} 35^{\prime}$ & $33^{\circ} 05^{\prime}$ & 3.6 & 0.93 & $213.7,14.0$ & & 7 & I \\
\hline 12 & 1984-05-17 & $11: 56$ & $120^{\circ} 30^{\prime}$ & $33^{\circ} 05^{\prime}$ & 3.3 & 1.0 & $36.1,13.2$ & $221.1,22.9$ & 6 & III \\
\hline 13 & 1984-05-17 & 11:59 & $120^{\circ} 30^{\prime}$ & $33^{\circ} 05^{\prime}$ & 3.4 & 0.80 & $198.6,7.5$ & $333.6,7.5$ & 4 & III \\
\hline \multicolumn{11}{|c|}{ After southern Yellow Sea M6.2 earthquake } \\
\hline 14 & $1992-05-29$ & 16:33 & $120^{\circ} 38^{\prime}$ & $33^{\circ} 29^{\prime}$ & 3.3 & 0.93 & $226.8,15$ & $24.3,22.5$ & 4 & III \\
\hline 15 & $1992-08-19$ & $07: 49$ & $120^{\circ} 58^{\prime}$ & $33^{\circ} 40^{\prime}$ & 3.0 & 0.97 & $25.7,15$ & & 4 & $\mathrm{I}$ \\
\hline 16 & $1992-08-25$ & 03:21 & $121^{\circ} 42^{\prime}$ & $34^{\circ} 12^{\prime}$ & 4.1 & 0.86 & $232.6,11.2$ & & & I \\
\hline 17 & $1992-10-25$ & $17: 46$ & $120^{\circ} 34^{\prime}$ & $32^{\circ} 45^{\prime}$ & 3.5 & 0.83 & $135.4,8.6$ & & 12 & I \\
\hline
\end{tabular}

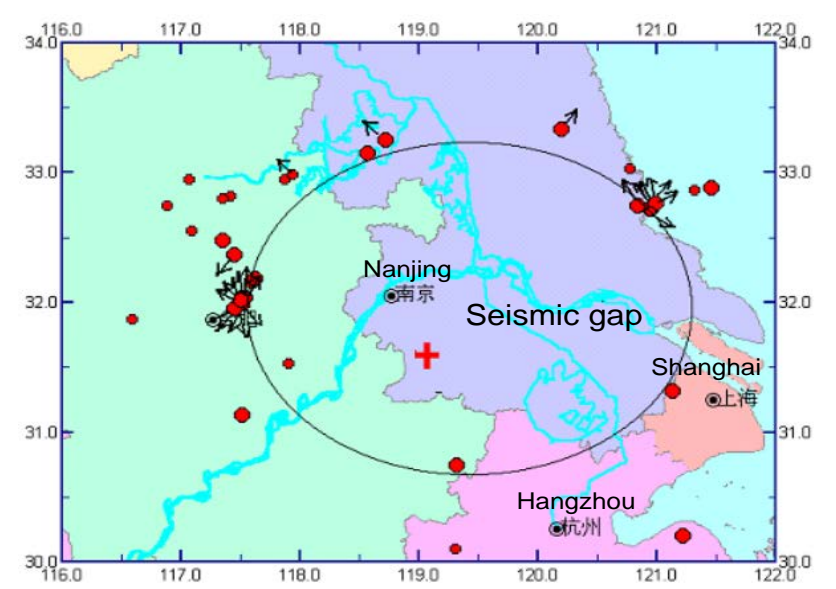

Figure 7. Primary rupture direction of small and medium earthquakes on the seismogeniczone of Liyang M6.0 earthquake

Fig. 7 shows the primary rupture directions of small and medium earthquakes on the seismogenic zone that occurred before the Liyang earthquake. Fig. 7 displays the primary rupture directions of other small and medium earthquakes that occurred in the same area. From Fig. 7 it can be clearly seen that except for the $\mathrm{M}_{\mathrm{L}} 3.1$ earthquake in January 28, 1978 , the primary rupture directions of all other earthquakes that occurred at the edge of the seismogenic zone either pointed out from the zone or were tangent to it. Further investigation showed that the $\mathrm{M}_{\mathrm{L}} 3.1$ earthquake has two possible primary rupture directions, one of which was $290.8^{\circ}$ which pointed out from the zone and the other one was $28.3^{\circ}$ and pointed into this zone. Therefore, its certainty factor was III. Another characteristic is that those primary rupture directions were consistent. $\lambda$ of directions of 8 earthquakes were close to $300^{\circ}$ and the azimuth angle of the directions of other 7 earthquakes were around $210^{\circ}\left(30^{\circ}\right)$ (Table 3). Those directions were roughly parallel to the main shock's nodal planes. However, as shown in Fig. 8, the primary rupture direction of the earthquakes occurred during normal periods (the periods during which no earthquake occurred and no anomalies were observed) were disorganized.

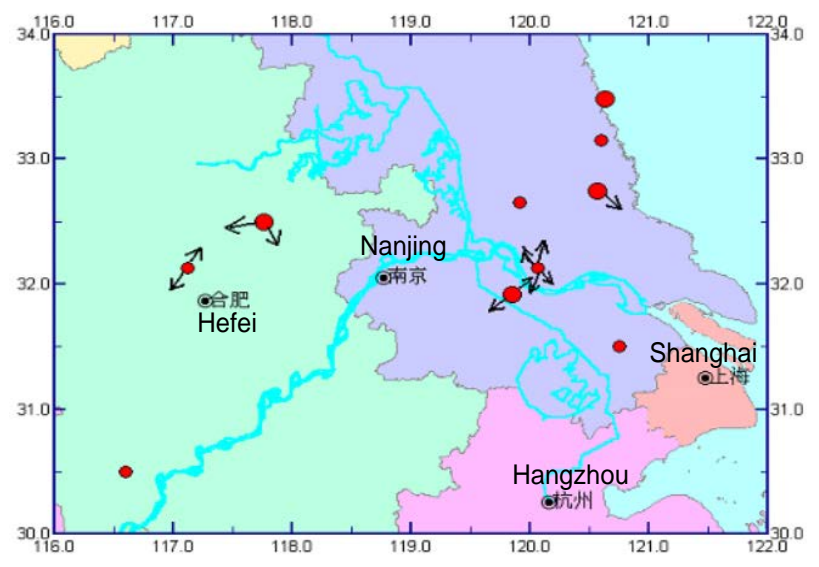

Figure 8. Primary rupture direction of small and medium earthquakes that occurred during normal periods in Liyang area

(2) The primary rupture directions of earthquakes that occur on seismic belts are either close to the direction of the belt or conjugated to it (close to the direction of the main shock's primary rupture plane), and point to the same direction. For the earthquakes that occur during the normal periods, theirprimary rupturedirectionsvary in different areas.

Let's use the southern Yellow Sea M6.2 earthquake as an example. The calculated results of rupture characteristics of medium and small earthquakes that occurred before and after that main shock were listed in Table 4 .

Fig. 9 displays primary rupture directions of small and medium earthquakes occurred on the seismic belt before the southern Yellow Sea earthquake. From that figure, it can be seen that most primary rupture directions were consistent with this seismic belt's direction and pointed to southwest 
(SW) except for three earthquakes: $\mathrm{M}_{\mathrm{L}} 3.3$ occurred at 11:56 on 1984-5-17, $\mathrm{M}_{\mathrm{L}} 3.4$ occurred at 11:59 on 1984-5-17, and $\mathrm{M}_{\mathrm{L}} 3.3$ occurred at 5:00 on 1983-10-14. Each of the three earthquakes had two candidate primary rupture directions and one of them pointed to SW. The other rupture direction of the first earthquake pointed to northeast (NE), and the other rupture directions of the rest two earthquakes pointed to northwest (NW) and conjugated to the direction of this seismic belt. The CF of those earthquakes was III. As stated in[23], for this seismic belt, the azimuth of nodal plane 1 was $350^{\circ}$ and the one of nodal plane 2 was $77^{\circ}$. Based on the distribution of the plotted primary rupture directions, we determined that the nodal plane 2 was the primary rupture plane which extended to northeast (NE).

Fig. 10 shows the primary rupture directions of small and medium earthquakes occurred in the same area (the southern Yellow Sea earthquake's belt) during normal periods. These directions either pointed to SW or NE, which were approximately consistent to the belt's direction.

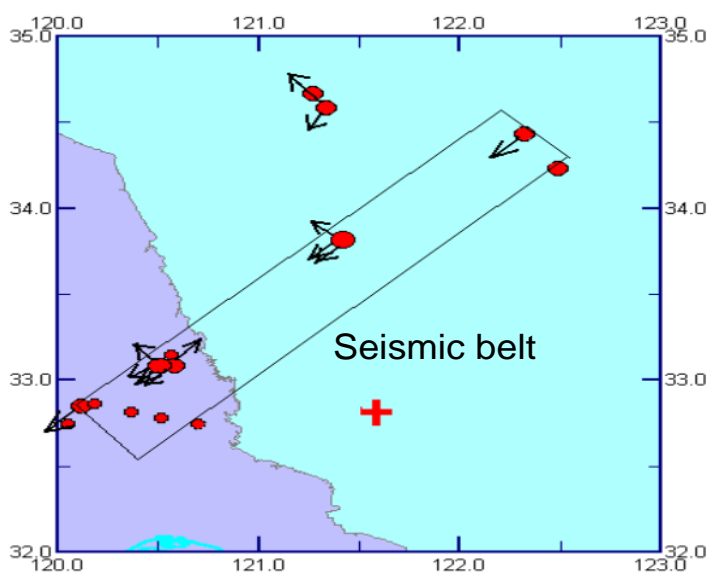

Figure 9. Primary rupture direction of small and medium earthquakes occurred on the seismic beltbefore southern Yellow Sea M6.2 earthquake

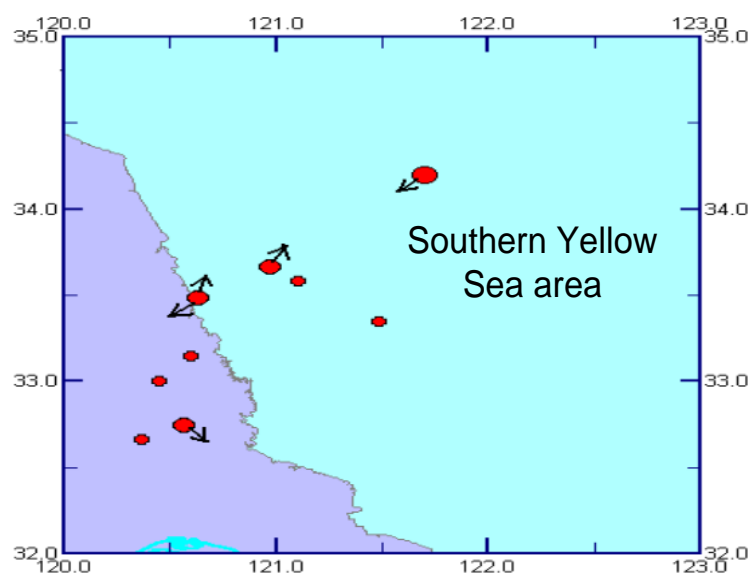

Figure 10. Primary rupture direction of small and medium earthquakes occurred during normal periods in southern Yellow Sea area

(3) The average ambient stress $\tau$ of the small and medium earthquakes that occur in a year before the main shock and within $200 \mathrm{~km}$ from the epicenter increases and changes acutely. However during the normal periods, this stress value is low and varies smoothly. It was also found that during the time periods from several months to 2 years before the main shock, the temporal periodicity of waveform $r$ changes violently and several lower values might appear. In the normal periods $r$ is comparatively higher and changes gently.

Fig. 11 plots the variation of ambient shear stress of the Liyang M6.0 earthquake sequence and its abscissa is sequence number of the earthquakes. From that figure, it can be found that before the main shock (especially in 1 year) the shear stress value was higher and varied more violently while in other time that value was lower and varied smoothly. This phenomenon can also be seen from the calculated expected value $\tau 0$ and RMS $\sigma$ of $\tau$ of earthquakes that occurred before the main shock (09/10/1977 07/08/1979) and during normal periods $(01 / 25 / 1992 \sim 10 / 25 / 1992)$, as shown in Table 5.

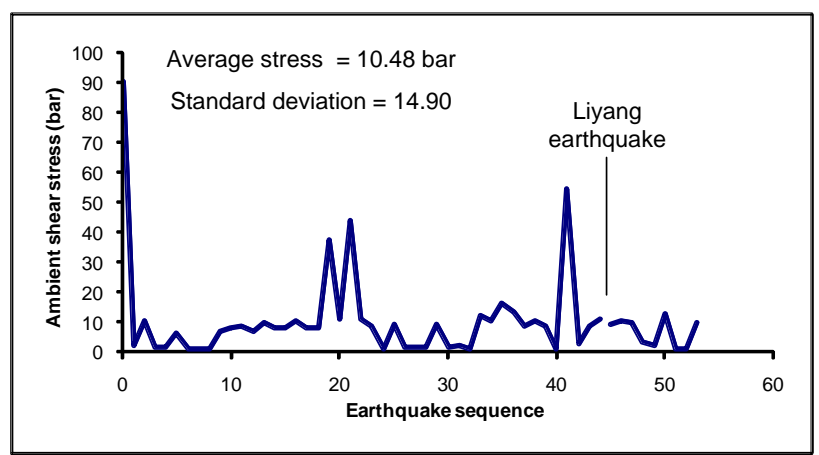

Figure 11. Ambient shear stress $(\tau)$ of small and medium earthquakes inLiyang M6.0 earthquake sequence

Table 5. Expected value and RMS of $\tau$ during different periods in Liyang M6.0 earthquake sequence

\begin{tabular}{|c|c|c|c|}
\hline Time period & $\tau_{0}$ (bar) & $\sigma$ (bar) & Number of samples \\
\hline 9/10/1977 7/8/1979 & 10.0 & 1.8 & 43 \\
\hline $7 / 6 / 1978 \sim 7 / 8 / 1979$ & 12.7 & 2.8 & 25 \\
\hline $1 / 25 / 1992 \sim 10 / 25 / 1992$ & 6.7 & 1.5 & 9 \\
\hline
\end{tabular}

The variation of temporal periodicity of waveform $r$ is displayed in Fig. 12. That plot shows that the temporal periodicity changed violently from August 7, 1978 till the main shock and a number of low values appeared with the minimum 0.934. During other times the temporal periodicity was steady, whose value varied in the range $0.99 \pm 0.1$.

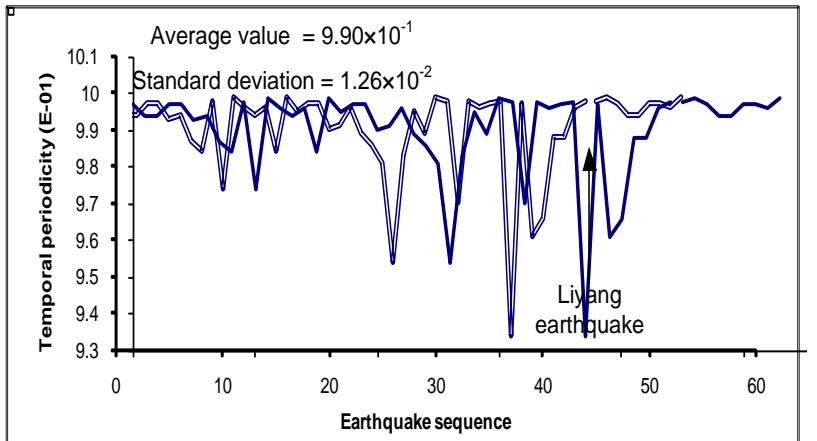

Figure 12. Waveform's temporal periodicity (r) of small and medium earthquakes inLiyang M6.0 earthquake sequence 
Fig. 13 displays the variation of ambient stress of the small and medium earthquakes in the southern Yellow Sea M6.2 earthquake sequence. It was found that the $\tau$ value dropped a little right before the main shock. Table 6 lists $\tau_{0}$ and $\sigma$ of $\tau$ during different time periods, which shows that during 3 years and 4 months before the main shock (especially 8 months before it), $\tau$ was higher and varied violently. However, during other time periods, that value was lower and steady.

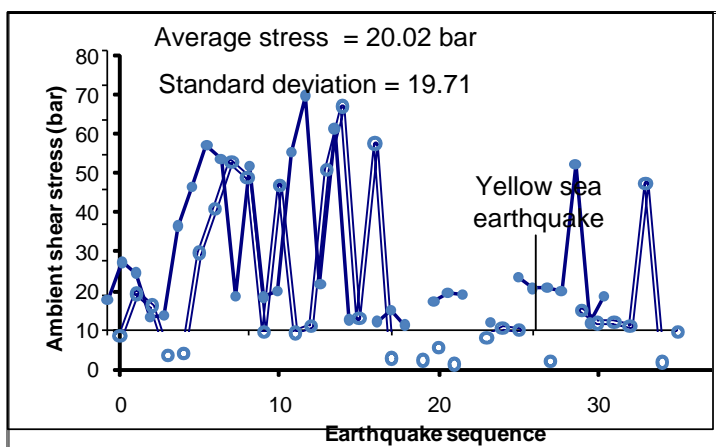

40

Figure 13. Ambient shear stress $(\tau)$ of small and medium earthquakes insouthern Yellow Sea M6.2 earthquake sequence

Table 6. Expected value and RMS of $\tau$ before and after southern Yellow Sea M6.2 earthquake

\begin{tabular}{|c|c|c|c|}
\hline Time period & $\tau_{0}$ (bar) & $\sigma$ (bar) & Number of samples \\
\hline $1 / 24 / 1978 \sim 5 / 17 / 1984$ & 24.4 & 5.0 & 20 \\
\hline $1 / 11 / 1981 \sim 5 / 17 / 1984$ & 20.3 & 5.8 & 15 \\
\hline $9 / 10 / 1983 \sim 5 / 17 / 1984$ & 19.2 & 6.4 & 13 \\
\hline $1 / 27 / 1992 \sim 10 / 25 / 1992$ & 13.9 & 5.1 & 8 \\
\hline
\end{tabular}

Fig. 14 describes the variation of temporal periodicity of waveform $r$. It is obvious that $r$ reached the lowest value of 0.963 at two months (3/7/1984) before the main shock. That value was higher and varied smoothly in the range of $0.99 \pm$ 0.01 in other time periods.

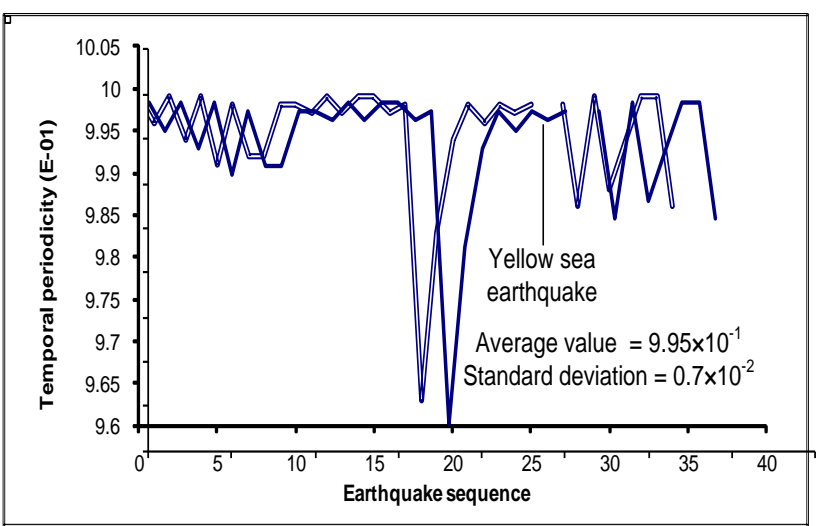

Figure 14. Waveform's temporal periodicity (r) of small and medium earthquakes insouthern Yellow Sea M6.2 earthquake sequence

Fig. 15shows the variation of ambient shear stress $\tau$ in the northern Gulf M6.1 and M6.2 earthquake sequence. Similar to the previous samples, the $\tau$ value had more and higher peak values and violently varied in the year before the M6.1 and M6.2 earthquakes. However, the $\tau$ value was low and varied smoothlyduring other time periods. Expected value and RMS of $\tau$ of earthquakes that occurred 3 years 9 months, 1 year 10 months, 1 year before the main shock, and that occurred during normal period were calculated and compared in Table 7, from which obvious differences can be observed.

Fig. 16plots the variation of temporal periodicity of waveforms $r$ in this earthquake sequence. From that figureitis observed that the temporal periodicity $r$ was higher and varied smoothly during most of the normal time periods while it reached the lowest value of 0.939 and violently varied from January 13, 1993 till the main shock.

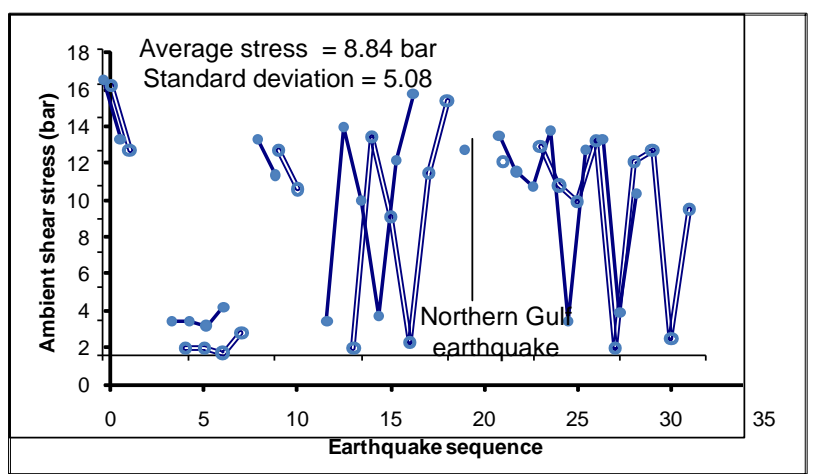

Figure 15. Ambient shear stress $(\tau)$ of small and medium earthquakes in northern Gulf M6.1 and M6.2 earthquake sequence

Table 7. Expected value and RMS of $\tau$ before and after northern Gulf earthquake sequence

\begin{tabular}{|c|c|c|c|}
\hline Time period & $\tau_{0}$ (bar) & $\sigma$ (bar) & Number of samples \\
\hline $3 / 9 / 1991 \sim 12 / 28 / 1994$ & 8.2 & 1.5 & 14 \\
\hline $2 / 22 / 1993 \sim 12 / 28 / 1994$ & 9.6 & 1.8 & 8 \\
\hline $1 / 2 / 1994 \sim 12 / 28 / 1994$ & 10.3 & 2.3 & 5 \\
\hline $3 / 12 / 1999 \sim 12 / 11 / 1999$ & 9.8 & 1.5 & 9 \\
\hline
\end{tabular}

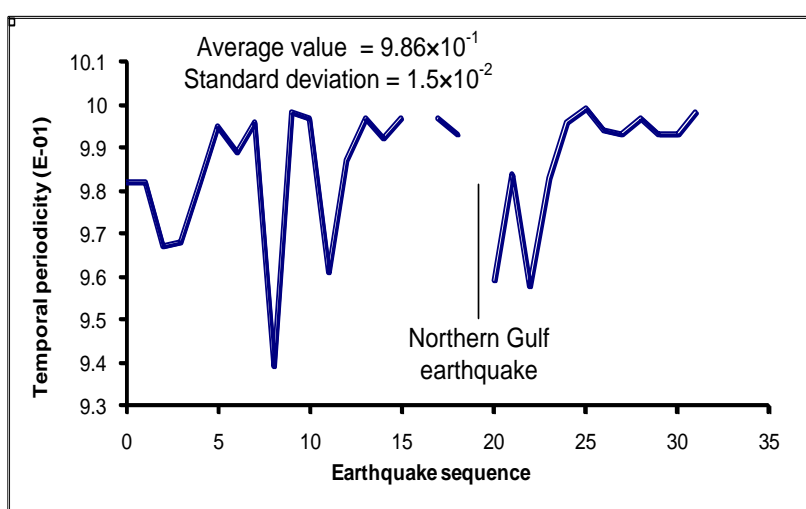

Figure 16. Waveform's temporal periodicity (r) of small and medium earthquakes in northern Gulf M6.1 and M6.2 earthquake sequence

(4) The strongest (or the second strongest) earthquake that occurs within $100 \mathrm{~km}$ from where the main shock occurs and within two years before it is defined as the single labeled foreshock of the main shock. It was found thatthe foreshock's ambient shear stress $\tau$ is several-fold higher than that of other earthquakes which occur in the same time period. $\mathrm{L}_{0} / \mathrm{L}$ of those foreshocks is close to 1 , which indicates a unilateral rupture. 
In the Liyang earthquake sequence, $\tau$ of regular earthquakes ranged from several to less than 20 bar. The maximum ambient stress is 90.3 bar which was recorded for the $M_{L} 4.6$ earthquake of May 10, 1977, and the second largest stress is 54.6 bar. The maximum value was calculated as the average value of the stresses which were recorded by five local seismic stations, which was reliable. $\mathrm{L}_{0} / \mathrm{L}$ of the $\mathrm{M}_{\mathrm{L}} 4.6$ earthquake was 0.95 , which was close to unilateral rupture. That earthquake occurred two years before the main shock and at $60 \mathrm{~km}$ from the main shock. Since the occurrence of the $\mathrm{M}_{\mathrm{L}} 4.6$ earthquake till the main shock, there was no stronger earthquake occurred within the distance of $200 \mathrm{~km}$ from the main shock. Therefore, the $\mathrm{M}_{\mathrm{L}} 4.6$ can be considered as the single labeled foreshock.

In the Heze earthquake sequence, the $\mathrm{M}_{\mathrm{L}} 4.6$ earthquake of December 23, 1981 occurred two years before the main shock and at $50 \mathrm{~km}$ from it. Till the occurrence of the main shock, it was the largest earthquake within $100 \mathrm{~km}$ and the second largest earthquake within $200 \mathrm{~km}$ from the epicenter of the main shock. Its $\mathrm{L}_{0} / \mathrm{L}$ was 1 , which belonged to unilateral rupture. The ambient shear stress of that earthquake was 170.7 bar, which was calculated as the average value of the stresses which were recorded by three local seismic stations. That value was evidently higher than the ambient shear stress of other earthquakes in the Heze sequence, thus, the $\mathrm{M}_{\mathrm{L}} 4.6$ earthquake was considered as the labeled earthquake of the Heze M5.9 earthquake.

(5) $\mathrm{L}_{0} / \mathrm{L}$ of the earthquakes occurring before the main shock is a little bit higher, but that difference is not so distinct. Also, there is no distinct variation regularity found for the $\mathrm{Q}$ value of $\mathrm{P}$ waves, and the width of Fourier spectrum before and after the main shock. Qvalue of the deep medium is higher, while that of the shallow medium is lower.

\section{Conclusions}

This paper introduces important seismic source parameters (stress drop, focal radius, etc.), characteristics of medium ( $Q$ value, amplitude of microtremor, etc.), and rupture characteristics $\left(\mathrm{L}_{0} / \mathrm{L}\right.$, primary rupture direction, ambient shear stress, and waveform's temporal periodicity), and explains how those parameters affect the small and medium earthquakes' focal mechanisms (direction of $\mathrm{P}$ axes, nodal plane solutions, etc.) through a number of earthquake examples. This paper reveals that the investigation of these parameters measured from small and medium earthquakes can be used as effective criteria in determining and judging impending main shocks that occur in same seismic zone. The findings of this paper can be further applied for advancing seismic wave method in earthquake prediction.

\section{REFERENCES}

[1] P.-S.Chen, Y.-R.Zhuo, Y.Jin, Z.-G.Wang, W.-Q.Huang,
W.-X.Li, R.-S. Hu, "Stress Field of Beijing, Tianjin, Tangshan, and Zhangjiakou Area Before and After Tangshan Earthquake”, Chinese Journal of Geophysics, 21(1), 1978, 24-58.

[2] X.-W. Hua, "Variation Process of Regional Stress in Beijing and Tianjin before and after the Tangshan Earthquake”, ActaSeismologicaSinica, 2(2), 1980.

[3] Z.-H. Xu, Y.-F.Liu, Y.-Z.Zhang, "Directional Characteristics of Seismic Stress Field in Beijing, Tianjin, Tangshang, and Zhangjiakou”, ActaSeismologicaSinica, 1(2), 1979.

[4] M.A. Sadovsky, I.L. Nersesov, S.K. Nigmatullaev, L.A. Latynina, A.A. Lukk, A.N. Semenov, I.G. Simbireva, V.I. Ulomov, "The Processes Preceding Strong Earthquakes in Some Regions of Middle Asia”, Tectonophysics, 14(3-4), 1972, 295-307.

[5] M.A. Sadovsky, I.L. Nersesov, "Forecasts of Earthquakes on the Basis of Complex Geophysisical Features", Tectonophysics, 23(3), 1974, 247-255.

[6] M. Wyss, "Precursors to the Garm Earthquake of March 1969”, Journal of Geophysical Research, 80(B20), 2926-2930.

[7] B.T. Brady, "Theory of Earthquakes II. Inclusion Theory of Crustal Earthquakes”, Pure and Applied Geophysics, 113(1), 1975, 149-168.

[8] C.-Z. Zhu, C.-H.Fu, S.-L.Luo, "Focal Parameters of Micro Earthquakes Occurred before and after Tangshan $\mathrm{M}_{\mathrm{L}} 7.8$ Earthquake”, ACTA GeophysicaSinica, 20(4), 1977.

[9] Y.-T. Chen, B.-H.Lin, X.-C.Li, M.-Y.Wang, D.-D.Xia, X.-H.Wang, W.-Q.Liu, Z.-Y. Li, "Determination of the Focus Parameters of the Small Earthquakes in Qiaojia, Shimian, and the Assessment of Seismic Hazard”, Chinese Journal of Geophysics, 19(3), 1976, 206-231.

[10] I.N. Gupta, "Precursory Reorientation of Stress Axes due to Vertical Migration of Seismic Activity”, Journal of Geophysical Research, 80(2), 1975, 272-273.

[11] H.-D. Gu, Y.-T. Chen, X.-L.Gao, Y. Zhao, "Earthquake Mechanism of Haicheng Earthquake in Liaoning”, Chinese Journal of Geophysics, 19(4), 1976, 27-285.

[12] M. Tsujiura, "Spectral Features of Foreshocks", Earthquake Research Institute, University of Tokyo, 52(3-4), 1977, 357-371.

[13] W.H. Bakun, T.V. McEvilly, "P-Wave Spectra for $M_{L} 5$ Foreshocks, Aftershocks, and Isolated Earthquakes near Parkfield, California”, Bulletin of the Seismological Society of America, 17(2), 1981, 423-436.

[14] R.B. Herrmann, "Q Estimates Using the Coda of Local Earthquakes”, Bulletin of Seismological Society of America, 70(2), 1980, 447-468.

[15] P.-S. Chen, J.-C.Gu, W.-X. Li, “A Study of the Earthquake Faulting Process and Earthquake Prediction in the Light of Fracture Mechanics”, Chinese Journal of Geophysics, 20(43), 1977, 185-202.

[16] C.-Z. Zhu, C.-H.Fu, Z.-G.Rong, S.-L.Luo, "Hypocentral Parameters and Quality Factor of Medium of Small Earthquakes Before and After Haicheng Earthquake”, ACTA GeophysicaSinica, 20(3), 1977. 
[17] Y.-Q. Zhu, W.-L.Liu, "Determination of Key Areas for Earthquake Surveillance and Protection during 2006-2020 in Shanghai”, Project Report, 2006.

[18] B.-H. Lin, S.-F.Wu, Z.-M.Gao, "On the Lowering of the Epicentral Intensity of the Ninghe Aftershock of May 12, 1977”, Chinese Journal of Geophysics, 22(1), 1979, 14-24.

[19] C.-Z. Zhu, K.-B.Shi, L.-T. Wang, "Variations in Microseism before and after the Tangshan Earthquake”, Chinese Journal of Geophysics, 24(3), 1981, 327-335.

[20] H. Kanamori, J.J. Cipar, "Focal Process of the Great Chilean Earthquake May 22, 1960”, Physics of the Earth and Plane- tary Interiors, 9, 1974, 128-136.

[21] W.-L. Liu, Y.-L.Xu, C. Zhang, H. Zhang, W.-D.Shen, W.-X.Zhong, "Study on the Distinguish Elements of The Seismic Wave of The Gap, Belt and Foreshock", Seismological Research of Northeast China, 22(2), 2006.

[22] W.-L. Liu and Y.-C. Liu, "Identify Criteria of Seismic Wave of Earthquake Gap, Earthquake Belt, and Foreshock“, ISET Journal of Earthquake Technology, 2011 48(1).

[23] Z.-C. Zhang, L.-G.Luo, H.-H.Li, L.-D.Chen, Y.-H. Li, “Chinese Earthquake Cases (1976-1980)”, Seismic Publisher, Beijing, China, 357-384. 